\title{
Juegos de lenguaje y teoría crítica. Sobre la recepción de Wittgenstein en el pensamiento de Albrecht Wellmer
}

\author{
Gustavo Matias Robles*
}

\begin{abstract}
Este artículo intenta ofrecer una lectura de la recepción de la filosofía de Wittgenstein en la teoría crítica de Albrecht Wellmer siguiendo básicamente dos líneas de lecturas: una centrada en la cuestión del lugar de la crítica y la otra centrada en su diferencia con otros representantes de la llamada Escuela de Frankfurt, básicamente con Habermas, Apel y Adorno. De este modo se intentará mostrar que la filosofía de Wittgenstein le ofrece a Wellmer las herramientas conceptuales para restituir el suelo mundano a una teoría crítica escéptica de fundamentaciones últimas.
\end{abstract}

Palabras clave: Wittgenstein. Wellmer. Teoría Crítica. Adorno. Habermas

Abstract: This paper sketch out an account of Albrecht Wellmer's reception of the philosophy of Ludwig Wittgenstein. What Albrecht Wellmer looks for in Wittgenstein is the possibility to answer the problem of the theoretical place of the criticism and the skills to argue with Adorno's messianic utopianism and Jürgen Habermas and Karl Otto Apel's idealizations and formalisms. Thereby the paper will show that Wittgenstein's philosophical-linguistic criticism enables Wellmer to recover the mundane ground for a skeptical critical theory of any foundationalisms.

Keywords: Wittgenstein. Wellmer. Critical Theory. Adorno. Habermas

\section{Introducción}

La obra de Albrecht Wellmer es una de las más potentes, actuales y sugestivas dentro de la rica tradición agrupada bajo el proyecto de la teoría crítica de la Escuela de Frankfurt; pero su suerte, al menos en el ámbito hispanohablante, ha sido la de permanecer a la sombra de la enorme sistematización habermasiana. La de Wellmer es una obra atravesada por preocupaciones variadas que se entrecruzan en una filosofía asistemática, con campos que se solapan y que encuentran su unidad dispersa en cierta vocación originaria de la teoría crítica: la voluntad de articular la reflexión teórica con un horizonte práctico de crítica social en discusión con lo más avanzado de la

\footnotetext{
* Universidad Nacional de La Plata/CONICET.
} 
conciencia filosófica de su época. La teoría estética, la ética, el lenguaje, la teoría de la racionalidad, el problema de la posmodernidad, el debate entre liberales y comunitaristas, la filosofía de la música, la idea de una teoría crítica o el pasado reciente alemán, todo esto confluye en la obra de Wellmer en una síntesis no sistemática que, como dice Honneth, se acerca más a la disonancia que a la armonía. ${ }^{1}$ En estas líneas me propongo simplemente recorrer algunas de estas reflexiones wellmerianas desde dos direcciones: desde su relación con la teoría crítica de la Escuela de Frankfurt, tradición que cuenta en él a uno de sus más auténticos representantes, y desde su recepción de la filosofía de Wittgenstein. En concreto: me propongo presentar la teoría crítica de Albrecht Wellmer focalizándome en su lectura de Wittgenstein para superar ciertas deficiencias que él diagnostica en las teorías de Habermas, Apel y Adorno en orden a pensar una teoría crítica del presente.

Asociada al programa de reformulación de la Teoría Crítica de Jürgen Habermas en términos de una racionalidad comunicativa la teoría crítica wellmeriana tomó, sin embargo, carriles y estilos un tanto diferentes con el paso de los años. A diferencia de Habermas, con quien trabajó en el doctorado y en la Habilitation, su madurez intelectual fue produciendo una obra más abierta y fragmentaria, alejada de la unidad y el carácter de proyecto que tenía la producción de su maestro. Mucho más receptivo a las criticas anti-ilustradas de la modernidad y cargado con una mayor preocupación estética que Habermas, Wellmer no se planteó el objetivo de completar el proyecto moderno, sino de rescatarlo a partir de sus fragmentos asumiendo positivamente la crítica postmoderna: para Wellmer, la posmodernidad era fundamentalmente el momento consciente de una tensión irresoluble de la modernidad, no su negación, sino su radicalización consecuente con sus propios potenciales críticos. Esta idea de una modernidad no utopista y desprovista de pretensiones fundacionalistas últimas la va a buscar Wellmer mediante una relectura de la tradición a la que él pertenecía, la teoría crítica de la Escuela de Frankfurt. Puntualmente Wellmer va a intentar establecer un diálogo entre la primera generación y la segunda generación de frankfurtianos

${ }^{1}$ Honneth, Axel, "Disonancias de la razón comunicativa. La teoría crítica y Albrecht Wellmer", en Honneth, A., Patologías de la razón. Historia y actualidad de la teoría crítica, Buenos Aires, Akal, 2009, p. 181. 
que parecía roto luego del giro lingüístico que había propiciado Habermas. En ese diálogo crítico es que la filosofía de Wittgenstein tendrá un papel central, tal y como pretendo mostrar en este trabajo.

\section{De Habermas a Adorno}

Albrecht Wellmer comienza su periplo intelectual intentando desarrollar la crítica a la racionalidad científica contenida en el nuevo paradigma comunicativo abierto por Habermas. Desde su tesis doctoral, en la que criticaba la fetichización del método de las ciencias experimentales de Karl Popper, siempre se esforzó por dar cuenta de una teoría que se entendiera como explicación de la realidad social e incentivación de los impulsos para una acción emancipadora en el espíritu de la teoría crítica frankfurtiana. Wellmer ve la posibilidad de llevar a cabo esto en la idea habermasiana de pretensiones universales de emancipación presentes en la praxis del entendimiento humano. Toda esta etapa de su obra queda patente en su Teoría Crítica y Positivismo de 1969. Allí emprende una ambiciosa relectura de Marx y de la primera generación de la teoría crítica mostrando los problemas que conlleva poner el foco de referencia normativo en el concepto de producción y en el enfrentamiento del hombre con su entorno natural, descuidando las interacciones sociales y comunicativas. Para Wellmer el problema de la teoría crítica de Horkheimer y Adorno sería el traslado de los supuestos productivistas de Marx al espacio de una fundamentación filosófica, ya que esto implicaba considerar a la praxis laboral como la verdadera praxis social racional. Esto daría lugar a una teoría mecanicista de la revolución que sólo confiaría en el desarrollo de las fuerzas de producción y dejaría en segundo plano la actividad política e ideológica. ${ }^{2}$ Ante esto, según Wellmer, habría que desmontar la filosofía de la conciencia contenida en el paradigma de la producción y mostrar que las esperanzas emancipatorias deben buscarse en las estructuras de la intersubjetividad lingüística. Este intento de recuperar la tradición marxista desde una filosofía de la comunicación quedaba más claro en un trabajo de 1977 llamado "Comunicación y emancipación" donde Wellmer afirmaba que su proyecto

2 Wellmer, Albrecht, Teoría crítica de la sociedad y positivismo, Madrid, Ariel, 1979, pp. 137156. 
consistía en una "reformulación analítico-lingüística del materialismo histórico"3 bajo la confianza de que el marxismo aún constituía una "expresión teórica de una misión de carácter histórico que pretende hacer de la comunicación libre de dominio el principio de la organización social". ${ }^{4}$ Wellmer era un claro ejemplo de que el programa habermasiano se mostraba en ese momento como una actualización del espíritu y la letra del marxismo.

Pero será en la década del ' 80 donde tanto la confianza en el programa habermasiano como en la tradición marxista comiencen a ser sometidos a crítica y donde la obra de Wellmer tome una fisonomía propia y original. Será en ese periodo en el que me voy a detener. En su libro Ética y Diálogo de 1986, Wellmer saldará cuentas con los intentos de fundamentación normativa de la ética comunicativa de sus maestros frankfurtianos Apel y Habermas, para proponer una ética sostenida en el diálogo situado y no en el discurso idealizado. No me voy a detener tanto en las propuestas éticas de Wellmer, sino en sus críticas a la ética del discurso y al modelo consensualista de verdad en el que ésta se apoyaba, ya que considero que en esas críticas se hace visible la necesidad de recurrir a una filosofía del lenguaje no fundacionalista. Esto es relevante ya que esta obra definirá las condiciones de su encuentro con Wittgenstein, aunque no sea precisamente en esa obra donde dicho encuentro se materialice. En Ética y Diálogo, Wellmer acepta la idea habermasiana del lenguaje como espacio de pretensiones de validez en el que se puede reconstruir las condiciones para un universalismo moral, pero este universalismo va a tener un carácter muy distinto debido a dos motivos: su rechazo a toda idealización de la comunicación y su rechazo a una separación radical de las esferas de validez. Me voy a detener en estos dos motivos para mostrar en qué medida a Wellmer le es necesario recurrir a Wittgenstein a los fines de pensar esas pretensiones de validez en un modelo no fundacionalista ni consensualista de lenguaje.

En cuanto al primer motivo -la crítica a la idealización de la comunicación- Wellmer critica a Apel y a Habermas su intento de fundamentar una ética discursiva sobre una teoría consensual de la verdad

3 Wellmer, Albrecht, "Comunicación y emancipación. Reflexiones sobre el «giro lingüístico» de la Teoría Crítica" en Isegoría. Revista de Filosofía Moral y Politica, No 1 , 1990, p. 31.

${ }^{4}$ Ibidem, p. 42, cursivas en el original. 
demasiado ligada a un esquema cognitivo y objetivista; esto provoca una idealización del consenso en un ideal regulativo, que se puede ver tanto en la idea de "situaciones ideales de habla" de Habermas como de "comunidad ideal de comunicación" de Apel. Para Wellmer, las obligaciones racionales (necesidad de asentir al mejor argumento) no determinan mandatos morales (la búsqueda de un consenso sobre el mejor argumento), y, mucho menos, si dichas obligaciones morales son pensadas en términos de un consenso descripto en términos formales como reglas de acuerdo, tal y como hacen Apel y Habermas. Tanto en la idea kantiana del reino de los fines como en la idea de situaciones idealizadas de Apel y Habermas hay un intento de explicar la conexión entre racionalidad y verdad para fundar un concepto de razón práctica, pero en ambos casos dejando de lado los espacios reales donde esa razón práctica debería tener lugar. Para Wellmer el carácter de ficción de estas idealizaciones "no radica en que estas presuposiciones se manifiesten repentinamente como falaces, sino en que dichas presuposiciones pretenden imponérsenos como ideales de la realidad, con lo cual disfrazan la historicidad y provisionalidad de todo sentido lingüístico". ${ }^{5} \mathrm{El}$ defecto de las éticas del discurso para Wellmer radica en que intentan fundamentarse en una "razón que se habría emancipado de las condiciones de su verbalidad", ${ }^{6}$ quedando por fuera de la pluralidad de los usuarios de signos y asentada en un sujeto trascendental que "se instala, por decirlo así, en la verdad". ${ }^{7}$ Esto supone una teoría de la reconciliación en el que el acuerdo tiene lugar por fuera de la historia y de sus condiciones sociales de articulación como algo "totalmente otro de la razón". ${ }^{8}$ Por lo tanto, para Wellmer lo que habría que plantear sería una elucidación de esas condiciones de verbalidad que la idealización comunicativa pierde de vista y restituir así la ética a su mundaneidad.

Esta vuelta a una pregunta por las condiciones reales de verbalización define otro perfil de la ética basada ahora en el diálogo y no en el consenso, en el que la búsqueda de un sentido idealizado del discurso es reemplazada por un proceso histórico y práctico de diálogo conducente a la "eliminación

\footnotetext{
5 Wellmer, Albrecht, Ética y Diálogo. Elementos del juicio moral en Kant y en la ética del discurso, Barcelona, Anthropos, 1994, p 109.

${ }^{6}$ Ibidem, p.115, cursivas en el original.

7 Ibidem, p. 114.

8 Ibidem, p. 117.
} 
del sinsentido". ${ }^{9}$ Es decir, una ética del diálogo basada en la búsqueda de nuevas formas de hablar y comportarse que reinterpreten las situaciones y eliminen desigualdades y exclusiones procesual y prácticamente, sin ideales regulativos ni sentidos últimos. Para Wellmer, en las cuestiones sobre moral de lo que se trata es de cómo entender la relación entre la fundamentación de la norma y la evaluación de la manera de actuar, ya que no es posible distinguir categóricamente, como pretende Habermas, las normas de su aplicación. Esta conexión entre la norma y su aplicación lleva a la segunda crítica de Wellmer a la ética del discurso, según la cual no es tampoco posible separar la esfera de validez moral de las otras esferas de validez. El punto sería pensar un concepto pluralista y abierto de racionalidad en el que las diferentes esferas discursivas, que Habermas y Apel ven como separadas, puedan entablar relaciones recíprocas, pero no "desde el punto de fuga de una comunidad ideal de comunicación, en el que la parcialidad de los momentos de la razón quede superada en un ideal moral unitario", ${ }^{10}$ sino en las prácticas mundanas de diálogo. Una ética planteada en términos discursivos y no fundacionalistas debería ser capaz de buscar la relación entre los discursos morales, estéticos y veritativos ya que "la racionalidad se manifiesta tanto por la capacidad para no confundir los diferentes puntos de vista, cuanto por la habilidad para relacionarlos mutuamente". ${ }^{11} \mathrm{El}$ universo del diálogo ético está constituido por discursos imposibles de aprehender desde "una tipología de pretensiones de validez fundada de manera pragmático-universal". ${ }^{22}$ Este interés en la intersección de las esferas más que en su autonomía es lo que define la necesidad de recuperar el concepto de juegos de lenguaje para pensar las prácticas comunicativas.

Es así que, con su crítica a las idealizaciones lingüísticas y a la separación estricta entre órdenes discursivos, Wellmer intenta pensar una ética del diálogo asentada sobre los juegos de lenguaje existentes y en las relaciones prácticas entre los discursos. El interés en la filosofía de las ciencias y en la teoría del conocimiento como llave para descifrar los potenciales de la racionalidad comunicativa da lugar ahora a dos intereses que van a tomar

\footnotetext{
9 Ibidem, p. 144.

${ }^{10}$ Ibidem, p. 182.

11 Ibidem, p. 183.

12 Ibidem, p. 188.
} 
prioridad en su obra a partir de los años 80: la preocupación estética y la pregunta por las condiciones de un orden democrático. Pero estas preguntas van a estar articuladas como una reflexión sobre el destino filosófico y cultural de la cultura occidental en el marco del debate sobre modernidad y posmodernidad que tuvo especial auge durante la década del 80 y del que Wellmer fue partícipe protagónico. En el marco de ese debate va a retomar la tradición de la primera generación de la teoría crítica, particularmente de la obra de Adorno, pero ya no para rechazarla de plano según las críticas que ya había formulado Habermas, ${ }^{13}$ sino para leerla inmanentemente. En los ensayos reunidos en Sobre la dialéctica de la modernidad y posmodernidad. La crítica de la razón después de Adorno, publicado un año antes de Ética y Diálogo, va a plantear, a partir de la estética y de la crítica al pensamiento identificante de Adorno, un marco de discusión para abordar las aporías de la modernidad y entender a la posmodernidad como un momento autorreflexivo de la Ilustración.

Wellmer retoma la filosofía estética de Adorno para pensar la relación entre entendimiento comunicativo y experiencia estética sobre la idea de que el campo de la estética puede quebrar la estructura tripartita de las dimensiones de validez del discurso (la verdad empírica, la adecuación normativa y la veracidad subjetiva) provocando una interferencia entre esas dimensiones y, por ende, abriendo el espacio para una revisión de sus límites y presupuestos. ${ }^{14}$ Pero esta idea de limitar la racionalidad comunicativa con la dimensión de la experiencia estética, o, mejor dicho, pensar la capacidad del arte moderno para definir el ámbito de la libertad individual, tiene que ser buscada por fuera de la autonomía de la experiencia estética, en las posibilidades de usos no estéticos y práctico-sociales del lenguaje. Lamentablemente, esa potencialidad crítica y desfetichizante de las esferas autónomas que Adorno confiere a la obra de arte pierde su suelo tan pronto es sacada de allí. Afirma Wellmer que "en Adorno sucede como si se hubiera

\footnotetext{
${ }^{13}$ Las críticas de Habermas a Adorno se encuentran en Habermas, Jürgen, El Discurso Filosófico de la Modernidad, Buenos Aires, Editorial Katz, 2008, pp. 123-149, y Habermas, Jürgen, Teoría de la Acción Comunicativa, Vol. I, Madrid, Editorial Taurus, 1990, pp. 480-508.

14 Wellmer, Albrecht, Líneas de fuga de la modernidad, Buenos Aires, Fondo de Cultura Económica, 2013, p. 225-240.
} 
proyectado un sistema tridimensional de categorías básicas sobre una superficie bidimensional", de modo que habría que "leerla estereoscópicamente, para darles a sus intuiciones filosóficas toda su vigencia frente a su propia sistemática". ${ }^{15}$ En concreto, esto significa que se debería rescatar las vocaciones y las intuiciones de la estética adorniana, pero dislocando su suelo sistemático, esto es reemplazando su paradigma idealista de filosofía de conciencia y su concepción instrumental del lenguaje por un modelo lingüístico de reflexión asentado en la crítica wittgensteiniana del significado.

Wellmer considera que el problema que se plantea Adorno es legítimo -los peligros de una racionalidad represiva y cosificadora-, así como también son legítimas las direcciones que tomaron sus intentos de solución -criticar tal racionalidad sin abandonarla-, sólo que Adorno carecía de las herramientas conceptuales adecuadas para ofrecer una respuesta viable al problema de la "dialéctica de la Ilustración". Son estas herramientas entonces, según Wellmer, lo que habría que restituirle al pensamiento de Adorno, ya que de otro modo no se podría dar con las diferenciaciones internas al concepto de racionalidad que permitirían extraer todas las consecuencias posibles del carácter "dialéctico" de la "Ilustración". Esto porque en Adorno la razón es totalizada como razón identificadora que violenta lo no idéntico, y el concepto es puesto como falseamiento de la realidad e injusticia contra lo particular bajo el principio de autoconservación y dominio técnico sobre el mundo natural. Ante este diagnóstico oscuro queda la pregunta: “¿cómo se puede pensar aún una sociedad humana y liberada, cómo la verdad, la libertad y la justicia, si el sistema de enmascaramiento de la racionalidad instrumental, si cosificación y olvido de la Naturaleza vienen instalados ya en las mismas condiciones de existencia del pensamiento conceptual?"16 Es decir, cómo se puede articular discursivamente un modelo de crítica que, a la vez, logre ofrecer la perspectiva de un proyecto histórico futuro.

En definitiva, Wellmer considera que Adorno sólo es capaz de ofrecer una solución a este problema apelando a una "filosofía de la redención", saliendo del lenguaje y de toda racionalidad históricamente situada para

15 Wellmer, Albrecht, Sobre la dialéctica de modernidad y postmodernidad. La crítica de la razón después de Adorno, Madrid, Visor, 1993, p. 155.

16 Ibidem, p. 100. 
colocar las bases normativas del discurso crítico en un más allá que adquiere características teológicas inviables históricamente. Así, las bases normativas de la crítica están puestas en un estado de redención final a-histórico y no conceptualizable. Con esta "articulación del motivo materialista de la emancipación y del motivo teológico de la redención"17, Adorno cierra toda posibilidad de encontrar esos criterios de la crítica de modo inmanente y racional, viéndose obligado a postular una instancia de trascendencia e incapaz de ofrecer una auto-comprensión cabal de la modernidad. Así, la pretensión de "rescatar la metafísica en el instante de su hundimiento" en Adorno está ligada, según la lectura de Wellmer, con un "impulso por el que la metafísica transciende todo lo existente en dirección hacia un absoluto"18 que se presenta como aporético en la medida en que no puede ser pensado como un ente (eso sería la ideología del idealismo), ni como no-ente (eso sería positivismo con su denegación de sentido a lo no verificable). El carácter aporético de este intento es el contenido de la filosofía de Adorno y es lo que Wellmer rechaza. Es así que, para rescatar ese impulso antimetafísico, va a acudir al pensamiento de Wittgenstein y aquí es donde nos vamos a detener ahora.

\section{De Adorno a Wittgenstein}

En su intento de pensar la postmodernidad como momento autocrítico de la modernidad Wellmer identifica tres grandes líneas de la "crítica de la razón y del sujeto"19 desde las que debe partir la conciencia filosófica postmoderna: la crítica psicológica del sujeto, la crítica de la razón instrumental o de la lógica de la identidad y la crítica del significado. La primera de ella consiste en "el descubrimiento de lo Otro de la razón en el interior del sujeto" 20 a partir de la constatación de un factum irracional inherente al sujeto autónomo, crítica que se encuentra ligada naturalmente a las figuras de Freud y Nietzsche. La segunda crítica es una radicalización de la

\footnotetext{
${ }^{17}$ Ibidem, 23

18 Wellmer, Albrecht, Finales de Partida. La Modernidad Irreconciliable, Valencia, Frónesis, 1993 , p. 224

19 Wellmer, Sobre la dialéctica de modernidad y postmodernidad, p. 74.

20 Ibidem, p. 76
} 
primera a partir de las reflexiones de la primera generación de la Escuela de Frankfurt y del postestructuralismo francés, y que consiste en develar las relaciones de dominio y violencia que se esconden en la misma racionalidad discursiva. Por último, se encuentra la crítica del sujeto constituyente del sentido en la filosofía del lenguaje que se vincula con Wittgenstein y su crítica a la idea de un fundamento subjetivo de las significaciones lingüísticas. En resumen, estas tres corrientes definen el paisaje de la crítica del postmodernismo filosófico al racionalismo y cuya diferenciación sería relevante para establecer lo que sería una forma de reflexión moderna de una postmoderna. Para Wellmer es sólo la tercera de estas críticas, es decir la crítica al significado, la que sería capaz de resolver las aporías que dejan planteadas las primeras dos críticas y la que ayudaría a forjar una filosofía postmoderna que se constituya como autorreflexión de una modernidad inacabada. Para lograr esto es que Wellmer emplea la filosofía de Wittgenstein como una linterna que ayuda a repensar los problemas que la filosofía adorniana no era capaz de resolver. Me voy a detener en esta estrategia de lectura.

Como mostré, según Wellmer, en su crítica al pensamiento identificante Adorno había denunciado la reducción de la razón discursiva a órgano de control y manipulación en el que concepto, significado lingüístico y lógica formal quedaban homologados. Como vimos, esta crítica daría como resultado la visión de un mundo autocentrado, cerrado, unidimensional, planteando la incómoda pregunta por cómo articular discursivamente un modelo de crítica que logre ofrecer la perspectiva de un proyecto histórico futuro. Para lograr salir de esta encrucijada, Wellmer considera que "no es necesario ir más allá de la razón discursiva para pensar una 'coherencia' más allá de la presión sistematizadora", ya que "la perspectiva normativa de una unidad sin presiones está más bien inserta en los fundamentos lingüísticos de la propia razón discursiva", ${ }^{21}$ y es la crítica filosófico-lingüística a la razón la que ofrece las herramientas para pensar eso. Para Wellmer, las aporías de Adorno se producen porque él asume una "crítica sociológica de la racionalidad instrumental" y una "critica psicológica del sujeto", pero sin plantear una "crítica del sujeto constituyente de sentido en la filosofía del lenguaje". ${ }^{22}$ Lo que esta última perspectiva ofrecería es, dicho sintéticamente, la evidencia de

21 Ibidem, pp. 99-100.

22 Ibidem, p. 88. 
un cuasi factum previo a toda subjetividad y a toda intencionalidad: sistemas lingüísticos de significaciones, formas de vida y un mundo abierto lingüísticamente, práctico, sujeto a cuestión y resignificación constante. Esta propuesta wittgensteniana supone el descubrimiento de un mundo en común al interior de la razón y del sujeto del cual deben venir los apoyos para la crítica que, a su vez, destruye los presupuestos de la filosofía de la conciencia asentado en la idea de un sujeto dador de significados. El desarrollo de esta crítica es lo que podría ofrecer la buscada filosofía de la postmodernidad como radicalización del proyecto moderno y no como su negación.

Para aclarar el marco de estas reflexiones conviene aclarar brevemente de qué se trata esa crítica filosófica-lingüística. Wittgenstein comienza sus Investigaciones Filosóficas con una crítica a las definiciones ostensivas que es también un ajuste de cuentas con ciertos presupuestos de su obra temprana. Allí intentaba despegar el concepto de significado de cierta interpretación racionalista que, entre otros lugares, se encontraba expresada en su mismo Tractactus Logico-Philosophicus en donde el lenguaje era visto como una red arrojada sobre las cosas, como existiendo por fuera de la realidad y relacionado exteriormente con ella como un espejo o una pintura. Esta "concepción pictórica" del lenguaje implicaba también la idea de que el sujeto sería, con sus vivencias e intenciones, la fuente última de las significaciones lingüísticas, reproduciendo así el marco mentalista de la tradición filosófica al menos desde Descartes, según el cual la constitución del significado se pensaba como el acto de una conciencia que produce intelecciones luego sintetizadas en estados mentales o imágenes cognitivas. El pensamiento era visto en estas reflexiones como algo privado y oculto que corría paralelo a la dimensión semántica del lenguaje. ${ }^{23}$ Eso será replanteado por el denominado "segundo Wittgenstein" a partir de un análisis de los modos de uso del lenguaje, lo que permitirá definir en otros términos la relación entre intención y acción; es decir, el clásico problema cartesiano de la relación entre el mundo y la mente estará referido ahora, no ya a un marco trascendental de actos de conciencia, sino al análisis mundano de los significados lingüísticos.

Con este giro la pregunta por el estatus de la comprensión deja de estar

${ }^{23}$ Cabanchik, Samuel, Wittgenstein. Una introducción, Buenos Aires, Editorial Quadrata, 2010, pp. 51-59. 
vinculada a estados mentales que hacen referencia a estados de cosas externos, para referirse ahora al conjunto de prácticas lingüísticas ya que "el significado de una palabra es su uso en el lenguaje": ${ }^{24}$ la pregunta por el conocer es retraducida en este análisis en términos prácticos y se asienta, no en la adecuación cognitiva entre contenidos mentales y cosas sino, en la capacidad o incapacidad de seguir una regla, en las aptitudes para proseguir prácticamente una secuencia, para ser participante de una acción socialmente establecida. En su famoso análisis de las definiciones ostensivas, Wittgenstein rechaza la idea de que el significado pueda ser definido ostensivamente, es decir, mediante una señal mental que acompañe al gesto corporal de relacionar una expresión con un objeto en el mundo. Esta poderosa mitología, cargada de implicaciones metafísicas y que da forma a nuestra comprensión fallida del funcionamiento del lenguaje, es lo que Wittgenstein se propone elucidar. La imagen criticada es la de que el signo adquiere significación cuando un usuario del lenguaje coordina algo con ese signo, un nombre con su significado o una expresión con un sentido ya dado. Esto supone una idea profundamente anclada en la conciencia filosófica occidental, según la cual existiría un sujeto que enlaza esos signos con su significado atribuyéndose así un carácter constituyente, y, por otro lado, supondría que los significados son entidades disponibles de antemano para un usuario. Wittgenstein comienza una crítica filosófico-lingüística que destruye al sujeto como autor y juez de sus propias intenciones de sentido, y son las consecuencias que se desprenden de esa crítica las que Wellmer considera apropiadas para plantear ciertos problemas teóricos de la modernidad.

Si bien Wellmer acepta que este reconocimiento de un mundo de significaciones preexistentes al sujeto no es exclusivo de Wittgenstein (el estructuralismo como la hermenéutica fueron decididos enemigos de toda visión intencionalista de la significación), en los principales conceptos de Wittgenstein, como los de regla y juegos de lenguaje, se guardaría también una distancia contra un posible objetivismo estructuralista, contra un conservadurismo hermenéutico o contra algún escepticismo deconstruccionista. Es decir, mientras el objetivismo estructuralista descuida la dimensión pragmática de una relación de significación no objetivable y

${ }^{24}$ Wittgenstein, Ludwig, Investigaciones Filosóficas, Buenos Aires, Altaya, 1999, p. 61 (\$ 43). 
esencialmente abierta, el escepticismo postestructuralista vuelve incontrolable el proceso de significación. Por el contrario, para Wellmer, "la vida del sentido lingüístico no se deja reducir a la vida anónima del código lingüístico, ni se retrotrae a un incontrolable juego de diferencias", 25 sino que puede ser mejor pensada en términos de seguimiento de reglas como lo hizo Wittgenstein. Pero estas reglas no aluden a algo constitutivo trascendentalmente ni a un ideal regulador, sino a la praxis intersubjetiva en la que alguien debe ser adiestrado en el uso de los juegos de lenguaje para poder participar, pero cuyo uso sólo encuentra sus criterios en el uso mismo. Es por esto también que "hablar un lenguaje forma parte de una actividad o de una forma de vida", 26 es decir, de un conjunto de actividades lingüísticas y no lingüísticas, prácticas, instituciones encarnadas y materiales con consecuencias prácticas. Es por esto que Wittgenstein concibe a las significaciones como esencialmente abiertas en la medida en que las expresiones se sostienen únicamente mediante el uso de la expresión, y su identidad es simplemente el indicador de diferencia con respecto a otros usos o a otros hablantes. Esto niega que las significaciones sean algo ideal, psicológico o dado en la realidad, y muestra al significado como un conjunto de reglas que no se fundan sino en la práctica de su aplicación a casos concretos, que están por principio abiertas, ya que vulnerar la relación de significación no conlleva ninguna contradicción lógica ni una falta moral, sino sólo una sanción en el marco de ese mismo juego, y que admite ser aclarada mediante el recurso a una pluralidad de situaciones de uso de un signo lingüístico. Una regla de significación está ahí como un "indicador de caminos" para el cual no hay una sola interpretación, pero que, sin embargo, no deja ninguna duda abierta acerca de cuál camino tomar. ${ }^{27}$

Para Wellmer esta crítica filosófico-lingüística de la filosofía del sujeto conduce al descubrimiento de "lo otro" de la razón en el interior de la razón, pero en este caso no se trata de fuerzas libidinosas o de relaciones de poder como en el postestructuralismo o en la primera generación de la Teoría Crítica, sino "del descubrimiento de un cuasi-factum, previo a toda intencionalidad o subjetividad: sistemas lingüísticos de significaciones, formas

\footnotetext{
25 Wellmer, Sobre la dialéctica de modernidad y postmodernidad, p. 84.

26 Wittgenstein, Investigaciones Filosóficas, p. 39 (\23).

27 Ibidem, p. 105 ( ( 85$)$.
} 
de vida, un mundo que en cierta forma se nos abre lingüísticamente", ${ }^{28}$ No se trata de pensar un mundo por fuera de la historia como en Adorno, sino de una "comunidad siempre en curso de realización" 29 y accesible lingüísticamente sobre un entendimiento mutuo que establece la posibilidad de diferenciar entre verdadero y falso, razonable o no. Así es como Wellmer interpreta el pasaje en el que Wittgenstein dice que "a la comprensión por medio del lenguaje pertenece no sólo una concordancia en las definiciones, sino también (por extraño que esto pueda sonar) una concordancia en los juicios" 30 . Mediante Wittgenstein lo que Wellmer lleva a cabo es una "metacrítica de la crítica del concepto" de Adorno como una reformulación de sus problemas para mostrar que la simple idea de una crítica al concepto identificador supone un lugar por fuera del lenguaje, y que, por ende, habría en Adorno un prejuicio intencionalista respecto al lenguaje, un "resto de ingenuidad filosófica" en sus pensamientos. Sólo recordar el lenguaje en el sujeto es lo que reconduciría la crítica adorniana por carriles no teológicos puesto que allí se hace visible la praxis comunicativa como lo que subyace siempre abierto a reformulación y lo que hace pensable una crítica al funcionamiento cosificador e identificante de la racionalidad.

Este énfasis no fundacionalista explica la referencia de Wellmer a la lectura de Saul Kripke en la que se defiende una posición decididamente escéptica con respecto al significado. En $O n$ Rules and Private Language, Kripke intentó sacar las consecuencias del argumento escéptico para hacer ver las dificultades en las que se cae cuando se sostienen criterios de corrección asentados en premisas fácticas como criterios de significatividad. Esta posición escéptica implicaría pensar el uso del lenguaje sin la necesidad de apelar a una instancia externa que lo justifique, sin ontología sustantiva alguna, y así radicalizar la idea de que los juegos del lenguaje definen sus propios límites sin pautas que establezcan condiciones normativas por fuera del mismo. Como define Kripke: "No puede haber nada que sea el querer decir algo mediante una palabra. Cada nueva aplicación que hacemos es un salto al vacío; cualquier intención presente podría interpretarse de modo que concuerde con cualquier cosa que pudiéramos elegir hacer. Por tanto, no

\footnotetext{
${ }^{28}$ Wellmer, Sobre la dialéctica de modernidad y postmodernidad, p. 83.

29 Ibidem, p. 85.

30 Wittgenstein, Investigaciones Filosóficas, pp. 217-218 (\$ 242).
} 
puede haber ni concordancia ni conflicto"31. Como señala Kripke, la solución al problema escéptico no consiste propiamente en responder a la pregunta escéptica, sino en rechazar el punto de partida objetivista que subyace a la misma, la idea de que hay un algo que garantizaría el acuerdo, sin que el acuerdo o el consenso puedan valer tampoco como candidatos posibles para ser instancias de fundamentación. La única vía que queda abierta en esta lectura escéptica de Wittgenstein es la reflexión sobre el papel que desempeñan en nuestro lenguaje el comprender, las intenciones o las significaciones, sin pretender remitirlas a algo por fuera de su uso. Para Kripke, desde la perspectiva de los participantes en el juego de lenguaje el escepticismo hermenéutico radical perdería sus pies, o en todo caso se trataría de un escepticismo ontológico y no epistemológico, que no dice que no podemos comprender, sino que no hay nada que nos garantice la corrección de esa comprensión que sin embargo efectuamos. Los hechos o las condiciones fácticas no son premisas del mundo social o de la comunidad, sino que esas condiciones fácticas pueden establecerse a partir del mundo social, internamente a partir de la gramática misma de los juegos de lenguaje ${ }^{32}$.

Pero se cuida Wellmer de las consecuencias nihilistas que podrían extraerse de esta lectura escéptica de Wittgenstein, ya que para él esta descentración del sujeto no legitima tampoco un anarquismo hermenéutico. Esto porque la significación remite a la idea de regla, es decir, a una forma de uso, por lo que no cabe la posibilidad de un desplazamiento infinito de la significación, ya que una regla no puede ser seguida de una sola ocasión, como tampoco puede pensarse en gobernar esa significación reintroduciendo al sujeto que interpreta. No se trata de que los signos alcancen su significación en cada acto de interpretación, sino que sólo entendemos el papel del "sujeto que interpreta" y el carácter abierto de las significaciones lingüísticas si las entendemos dotadas de un índice de generalidad en el que el nuevo uso de una palabra indica una nueva forma de comprensión, una nueva forma de vida. Es a partir de esta generalidad presente en el uso del lenguaje que

${ }^{31}$ Kripke, Saul, Wittgenstein a propósito de reglas y lenguaje privado. Una exposición elemental, Madrid, Tecnos, 2006, p. 69.

32 En esta lectura de la interpretación de Kripke he seguido el estudio de Karczmarczyk, Pedro, El argumento del lenguaje privado a contrapelo, La Plata, Edulp, 2011, pp. 243-262. 
Wellmer trata de pensar la posibilidad de resolver las aporías de la modernidad y de nuevas síntesis subjetivas y comunitarias sin un más allá del lenguaje. Es por esto que para Wellmer no hay que entender a Wittgenstein como un relativista, ya que de allí resultaría obvio buscar criterios que trasciendan los juegos de lenguaje a fin de salvar la razón como lo hicieron Apel y Habermas, sin ver el hecho de que el que "nunca tengamos otros criterios de verdad y racionalidad que aquellos que pertenecen a nuestro lenguaje no significa que no podamos trascender con razón nuestro lenguaje y los criterios que ese lenguaje comporta". ${ }^{33}$ Pero tampoco se deben leer las Investigaciones Filosóficas en términos naturalistas, que define que los problemas trascendentales del Tractactus son ahora planteados en términos de un análisis empírico. Por el contrario, a Wittgenstein habría que leerlo como un intento, no de naturalizar el sujeto cognoscente, sino de superar el idealismo mediante un análisis de la articulación lingüística del mundo de la vida, es decir, se trataría de una "filosofía trascendental sin pretensiones de fundamentaciones últimas y sin el parapeto de reconstrucciones sistemáticas". 34

Para Wellmer relativismo y absolutismo son dos caras de la misma moneda ya que "ambos tienen en común el intento de evaluar el juego de la verdad desde un metaperspectiva". ${ }^{35}$ Lo que se esconde aquí es la idea de la verdad como un ideal regulativo por fuera de nuestras prácticas lingüísticas: mientras el relativista se retira del juego de la verdad y lo observa desde afuera -al precio, por supuesto, de caer en contradicción performativa-, el absolutista trata de mostrarle al relativista que es necesario cierto criterio metadiscursivo como condición de posibilidad de ese afuera; pero, en definitiva, ambas posiciones se definen en relación a un criterio que permanece como ideal regulativo. Lo que habría que hacer entonces es abandonar todo ideal regulativo de la verdad, que "no nos ayuda ni a entender mejor esta praxis de juzgar y fundamentar ni a orientarnos mejor en ella", para así "salvaguardar el poder normativo de la verdad" que es inherente a la gramática de nuestros juegos de lenguaje. ${ }^{36}$ Remitiéndose a Sobre la certeza, afirma Wellmer que es en el marco de estas prácticas sociales donde tiene

\footnotetext{
33 Wellmer, Finales de Partida, p. 264.

34 Ibidem, p. 265, cursivas en el original.

35 Wellmer, Albrecht, Lineas de fuga de la modernidad, p. 129.

36 Ibidem, p. 130.
} 
lugar la relación entre verdad y justificación, y tal relación sólo es posible en un espacio social de razones sobre un conjunto de "verdades paradigmáticas" -aseveraciones o convicciones que no requieren justificación al interior de un juego de lenguaje, sino que definen las pautas elementales de una posible justificación en ese juego ${ }^{37}$. Con esto se intenta definir un concepto pragmatista de verdad no epistémico, es decir, un concepto de verdad que no se reduzca a su justificación (como en el Tractactus o en el empirismo lógico donde entender una proposición significa saber qué es el caso si ella es verdadera), ni entendido como ideal regulativo (como en el caso de Habermas y Apel para quienes verdadera es una opinión que puede ser aceptada bajo condiciones ideales como justificada), pero tampoco sin caer en el relativismo de negar toda pertinencia pragmática al concepto de verdad como en el caso de Rorty.

Entonces, "la descentración filosófica del sujeto, a diferencia de su descentración psicológica, no significa una herida infligida a nuestro narcisismo, significa más bien el descubrimiento de un mundo común, siempre en trance de franqueársenos en el interior de la razón y del sujeto". 38 Los motivos sobre los que se asientan las otras críticas a la razón y el sujeto la violencia simbólica, la voluntad de poder, la dominación social, etc. - están presentes en ese mundo y son problemáticos, pero por ser mundanos significa también que están abiertos lingüísticamente. Para Wellmer no habría que interpretar afirmativamente la crítica psicológica o la crítica del poder ya que, por ejemplo, toda violencia simbólica podría ser redescripta y reinterpretada al interior del mismo lenguaje. Pensar toda comprensión como rígidamente inmóvil es, después de Wittgenstein, una ficción racionalista, debido a que la gramática de nuestro lenguaje muestra múltiples formas de uso de las palabras sin que tengamos que tropezar con una significación primaria o fundamental. En términos que remiten a Adorno, afirma Wellmer que "en la vida del sentido lingüístico opera una fuerza mimética mediante la cual lo no idéntico en la realidad se refleja como no idéntico en las significaciones lingüísticas". ${ }^{39}$ Debido a tal fuerza mimética es que el mismo lenguaje está capacitado para cumplir lo que Adorno exigía como tarea de la filosofía: "ir con el concepto

\footnotetext{
${ }^{37}$ Ibidem, p. 125.

38 Wellmer, Sobre la dialéctica de modernidad y postmodernidad, p. 87.

39 Ibidem, p. 89.
} 
más allá del concepto"40. Es decir, la idea de un uso no cosificante del lenguaje se encuentra en el mismo lenguaje sin necesidad de alguna utopía de la reconciliación ni de idealización de un consenso. La apertura del lenguaje está dada porque en toda argumentación "chocan entre sí maneras de ver, planteamientos y usos lingüísticos" que hace que la vida del sentido alcance en ella una forma reflexiva al interior de las mismas prácticas, y es a esas prácticas del lenguaje a las que la teoría crítica debe volver.

Esta crítica filosófica-lingüística está presente también en las reflexiones políticas de Albrecht Wellmer. Así, en su muy comentado "Verdad, contingencia, modernidad" emprende una discusión con el universalismo liberal idealizado de Apel, Habermas y Putnam, y con el etnocentrismo relativista de Rorty. Contra estas posiciones, Wellmer trata de pensar los principios de una sociedad liberal como juegos de lenguaje abiertos y autorreflexivos, en los que las prácticas e instituciones de una cultura no pueden justificarse como un todo desde afuera. La ausencia de un punto arquimédico por fuera de nuestras prácticas significa que sólo podemos clarificar un juego de lenguaje, instituciones, principios o distinciones conceptuales desde adentro de esos juegos, tratando de reconstruirlos y volverlos coherentes, es decir, a partir del proceso de socialización en una de esas prácticas en cuestión. La comprensión de principios, instituciones y prácticas de una cultural liberal incluye "babits of heart", esto es, "juicios morales con reacciones emocionales y un entreveramiento de juicios morales con reacciones emocionales y con patrones de interpretación". ${ }^{41}$ Por lo que una defensa de los principios y prácticas liberales exige previamente estar socializado en esa cultura, aunque siempre sea posible un trabajo de traducción y diálogo intercultural al interior del juego de lenguaje liberal, ya que "hablar un lenguaje común no es el punto de partida de una argumentación, sino el resultado de ella". ${ }^{42}$

Con Wittgenstein intenta Wellmer mostrar que todo proceso de argumentación pública remite a un contexto de experiencia práctica sólo a partir del cual se puede hablar de algo así como las bases normativas del discurso liberal. Sin embargo, tal contexto de experiencia no debe ser pensado

\footnotetext{
40 Adorno, Theodor, Dialéctica Negativa, Madrid, Taurus, 1992, p. 17.

41 Wellmer, Finales de Partida, p. 186.

${ }^{42}$ Ibidem, p. 188.
} 
como cerrado porque la racionalidad lingüística que lo articula es esencialmente abierta, capaz de trascender los contextos locales. Para Wellmer habría que abandonar la idea de una fundamentación última de los principios liberales y democráticos y asumir el criterio de que lo propio de una cultura liberal es sólo la permanente posibilidad de discusión sobre la interpretación de esos principios. Pero para esto, es decir, para traducir la crítica postmoderna a una praxis postmoderna es necesario que los sujetos hagan suyas ciertas instituciones y prácticas; esto es lo que Wellmer denomina una "eticidad democrática". ${ }^{43}$ Es decir, para poder dar cuenta de la formación discursiva de una voluntad general el discurso democrático tiene que ser pensado no sólo como procedimientos garantizados en términos de derechos fundamentales, sino como formas de vida, como encarnados en posturas y prácticas cotidianas, como socializaciones afectivas y comprensivas que se justifican en su propia práctica.

\section{Consideraciones finales}

En estas líneas no fue mi idea una discusión sobre posibles interpretaciones de Wittgenstein ni una profundización sistemática de la obra de Wellmer, sino solamente ensayar una lectura de la necesidad de recurrir a Wittgenstein que tiene la teoría crítica de Wellmer para pensar el problema del lugar teórico de la crítica. Intenté mostrar que Wellmer toma las premisas y las condiciones de esta recepción de su relación con la tradición de la teoría crítica, fundamentalmente con Adorno y Habermas. De Habermas toma Wellmer la necesidad de que el análisis y su fundamentación sea ejercitado en el plano de un mundo articulado intersubjetivamente, de modo que, para evitar los atolladeros de una filosofía de la historia en clave especulativa, o de una filosofía de la conciencia, habría que reubicar la teoría crítica en el suelo de una filosofía del lenguaje, y desde ese lugar hacerse cargo del proceso de diferenciación interno de la racionalidad que caracteriza a la modernidad. De Adorno asume Wellmer su confianza en que la dimensión estética es capaz de poner en cuestión las autonomías y abismos entre las diferentes esferas sociales mostrando su solapamiento y lo precario de su cierre; esta experiencia de la porosidad exigía para Adorno la búsqueda de una racionalidad entendida

${ }^{43}$ Ibidem, p. 83. 
como "síntesis no coactiva de lo múltiple", tarea que Wellmer también hace suya. Pero tanto Habermas como Adorno resolvían sus exigencias con una estrategia similar que Wellmer rechaza: escapando del plano de las prácticas sociales reales, buscando en una idea mesiánica de reconciliación un concepto sustantivo de verdad en Adorno, o postulando un consenso idealizado de validez pragmática en el caso de Habermas. Ambas propuestas volvían a la teoría crítica incapaz de pensar la crisis de la modernidad como una oportunidad de autorreflexión ya que se salían del mundo y de la historia.

Esa intención de volver mundana a la teoría crítica es lo que intenté mostrar aquí como la gran apuesta de Wellmer en su recepción de la filosofía de Wittgenstein. Es en la crítica filosófico-lingüística del significado donde se le hace visible a la teoría crítica ese espacio en el cual buscar la posibilidad de resignificación y transformación de las prácticas sociales. Ese espacio no habría que buscarlo ni en idealizaciones ni en utopismos, sino en esas mismas prácticas articuladas lingüísticamente. La filosofía de Wittgenstein le ofrecía a Wellmer un dispositivo para traer la teoría crítica al mundo, a un mundo de juegos de lenguajes y reglas sin criterios externos, a un mundo en el que las relaciones sociales en tanto articuladas lingüísticamente pueden ser redescriptas al interior de su misma vida social haciendo arbitraria toda normatividad, sea en la forma de ideal regulativo, sea en la forma de horizonte utópico de emancipación. El Wittgenstein de Wellmer es un optimista mundano que se distancia del absolutismo de Apel, del formalismo de Habermas o del pesimismo mesiánico de Adorno. El Wittgenstein que le interesa a Wellmer es también un escéptico con respecto a las soluciones o legitimaciones últimas, pero que precisamente mediante ese escepticismo permite una "salvación filosófica de la razón y del sujeto" de los embates irracionalistas. Incluso "se podría decir que la salvación se encuentra en radicalizar un escepticismo", en "un regreso escéptico al common sense", ${ }^{44}$ mostrando que no existen límites para la argumentación racional y que las capacidades y esferas sociales no están separadas por un abismo. Esa perspectiva escéptica, pero no irracionalista, es la que muestra las posibilidades de sentidos que se abren en los juegos de lenguajes y donde la teoría crítica debería ubicarse sin mala conciencia.

${ }^{44}$ Wellmer, Sobre el dialéctica modernidad y postmodernidad, p. 111. 